\title{
The Mechanisms of Inhibition of Frog Endplate Currents With Homologous Derivatives of the 1,1-dimethyl-3-oxybutyl Phosphonic Acid
}

\author{
E. PRYAZHNIKOV ${ }^{1}$, A. OSTROUMOV ${ }^{2}$, O. DRUGININA $^{3}$, F. VYSKOČIL $^{4}$, \\ A. SKORINKIN ${ }^{2,3,5}$
}

${ }^{1}$ Kazan State Medical University, Kazan, Russia, ${ }^{2}$ Kazan Federal University, Kazan, Russia, ${ }^{3}$ Kazan Institute of Biochemistry and Biophysics RAS, Kazan, Russia, ${ }^{4}$ Institute of Physiology, Academy of Sciences of the Czech Republic and Faculty of Sciences, Charles University, Prague, Czech Republic, ${ }^{5}$ Institute of Informatics, Kazan, Russia

Received January 4, 2012

Accepted April 2, 2012

On-line June 6, 2012

\section{Summary}

The mode of inhibition of endplate currents by four esters of 1,1-dimethyl-3-oxybutyl phosphonic acid with different lipophilicities and molecule lengths were estimated by mathematical modeling based on previous electrophysiological data supplemented by several experiments with rhythmic stimulation. The aim was to discriminate between their receptor and non-receptor effects. It was shown that all esters have a two-component mechanism of depression: inhibition of the receptor open channel and allosteric modulation of the receptorchannel complex. The ratio of both functional components depends on the length and lipophilicity of the esters. Short and less lipophilic esters mostly act as open channel inhibitors and the rate of inhibition substantially depends on the rate of stimulation, i. e. probability of the receptor-channel opening. As the length of the ester radicals and their lipophilicity increased, these compounds were more active as allosteric receptor inhibitors, probably hindering the function of nAChRs from the lipid annulus.

\section{Key words}

Endplate potential - Nicotinic cholinoreceptor - Allosteric modulation • Open channel block • Lipophilicity and cholinergic effect

\section{Corresponding author}

F. Vyskočil, Institute of Physiology, Academy of Sciences of the Czech Republic, Vídeňská 1083, 14220 Prague, Czech Republic. E-mail: vyskocil@biomed.cas.cz

\section{Introduction}

Nicotinic acetylcholine receptors (nAChRs) are part of the superfamily of ligand-gated ion channels which are comprised of five subunits forming the central pore (Krůšek et al. 2004). They are receiving increasing attention due to the important role they play in human and veterinarian pathology (Taly et al. 2009). Different modulation actions might be potentially useful for the selective treatment of neuronal and neuromuscular disorders (Beránek and Vyskočil 1967, Zwart and Vijverberg 1997, Grutter and Changeux 2001) as well as for better understanding nAChRs activation and inactivation as representatives of ligand-gated C-loop channels (Svobodová et al. 2006).

In addition to competitive antagonists interacting with specific neurotransmitter binding sites, nAChRs can be affected by non-competitive inhibitors, which bind to other receptor protein sites (Krůšek 2004, Krůšek et al. 2004). They can have different molecular composition and physical and chemical properties (Romanelli and Gualtieri 2003). Non-competitive inhibitors usually do not directly affect agonist binding. Either they can act by blocking the ion channel or they induce an allosteric conformation of the segments in contact with the lipid annulus surrounding the receptor, or affect the lumen of the ion channel. (Romanelli and Gualtieri 2003, Shaihutdinova et al. 2009). 
The effects of several homologous derivatives of 1,1-dimethyl-3-oxybutyl phosphonic acid (DMOPA) namely its dimethyl-, diethyl-, dipropyl- and dibutyl- esters were recently studied on frog endplate currents (see Fig. 1 for structure). These compounds are organophosphorous agents with increasing molecule length aimed for potential medical use. One of these compounds, a dimethyl ester of DMOPA (Dimephosphon) is already explored in clinical practice for normalizing the central and peripheral vascular system and enhancing cerebral circulation (Penionzhkevich et al. 2004, Penionzhkevich and Gorbunov 2009). The aim was to discriminate between their receptor and non-receptor effects with help of computer modeling and assess the main sites of action on nAChR moiety for each compound.

The basic effects of these compounds on excitable membranes have already been presented and for modeling purpose, we quote from previous papers by Pryaznikov and co-workers (Pryazhnikov et al. 2005). In summary, these compounds did not affect the resting membrane potential of muscle fibers in vitro. The degree of lipophilicity estimated as the partition Overton-Meyer coefficient between octanol and the aqueous phase was less than 0.1 for DMOPA, 1.1 for dimethyl ester dimephosphon, 8.6 for diethyl ester, 89.4 for dipropyl ester, and $>1000$ for dibutyl ester respectively (see also Fig. 4). This corresponds with the well-known principle that lipophilicity increases exponentially with each carbon atom added to the ester radicals in homologous lines. In the voltage-clamp regime when spontaneous miniature endplate currents (MEPCs) and stimulationevoked endplate currents (EPCs) were recorded, the generic and most polar acid DMOPA had almost no effect on the amplitude and time course of these postsynaptic responses. However, the esters of this acid decreased the amplitude of MEPCs and EPCs. This decrease was concentration-dependent between 10 and $500 \mu \mathrm{M}$ and was similar for both MEPCs and EPCs. This fact clearly indicated that the main target of esters is nAChRs and not the number or size of quanta released by nerve stimulation. When applied at the most effective concentration of $500 \mu \mathrm{M}$, the esters decreased the EPC amplitude on average by $39 \%$ (dimethyl ester dimephosphon), $22 \%$ (diethyl ester), $47 \%$ (dipropyl ester) and $56 \%$ (dibutyl ester) respectively. Tests with the standard competitive antagonist (+)-tubocurarine showed that there is no competitive and reversible action of these compounds on the binding sites for $\mathrm{ACh}$ at
nAChRs. The esters also shortened the decay time for EPCs and MEPCs. The $\tau$ of EPC exponential decay, which was $1.56 \mathrm{~ms}$ in controls, decreased on average by $20 \%$ in $500 \mu \mathrm{M}$ diethyl ester, by $34 \%$ in dipropyl ester and by $39 \%$ in dibutyl ester at a holding potential of $-45 \mathrm{mV}$. However the treatment of endplates with $500 \mu \mathrm{M}$ dimethyl ester was exceptional. This drug changed EPC and MEPC decay from monophasic to biphasic, characterized by two exponential constants (Fig. 1C). The $\tau$ of the first rapid phase was shortened by $35 \%$ and the following slow one was increased by $125 \%$ compared to the controls having single exponential decay (Fig. 1A).

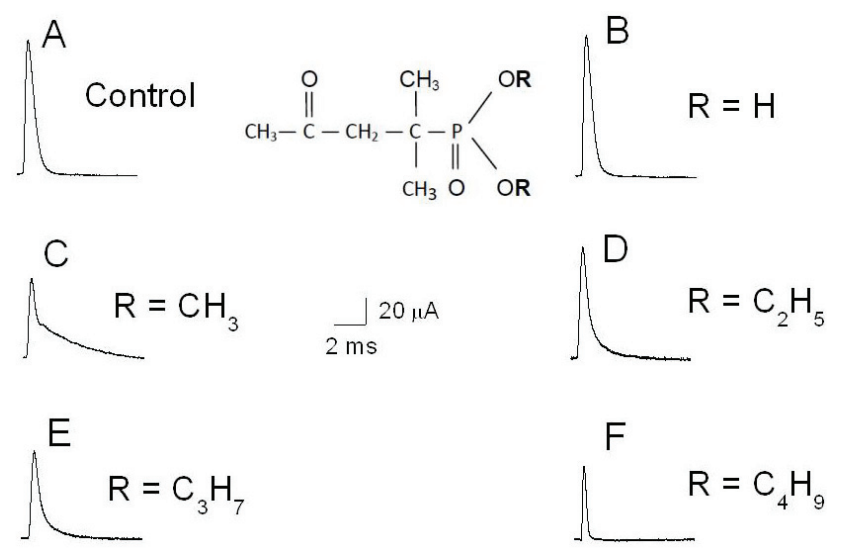

Fig. 1. Averaged 10 endplate currents (EPC) before (A, control) and after action of $500 \mu \mathrm{M}$ 1,1-dimethyl-3-oxobutyl phosphonic acid (B), its dimethyl ester (C), diethyl ester (D), dipropyl ester (E) and dibutyl ester (F). Stimulation frequency was once per $2 \mathrm{~min}(0.008 \mathrm{~Hz})$. Recordings from various endplates were normalized to the control amplitude (in $\mu \mathrm{A}$ ) and time scale (in $\mathrm{ms}$ ).

It is known that the time constant $\tau$ for endplate current decay depends exponentially on the membrane potential. $\mathrm{H}$ is the coefficient for the shift in membrane potential necessary for an e-fold increase of $\tau$. Under normal conditions, $\mathrm{H}$ is about $200 \mathrm{mV}$ in frogs (Magleby and Stevens 1972, Magazanik et al. 1982, Giniatullin et al. 1989). When $\mathrm{H}$ was studied after dimethyl ester application where biphasic decay was observed, the dependence of slow decay $\tau$ on changes in membrane potential was strongly decreased $(\mathrm{H}=502 \mathrm{mV})$ whereas the rapid decay $\tau$ became voltage-independent.

Both amplitude and time course changes recovered poorly when the drugs were washed out. The effectiveness of washing decreased with increasing molecule length and lipophilicity. For example, the effects of the least lipophilic dimethyl ester recovered by 
$66 \%$ whereas with the more lipophilic dibutyl ester, the washout effectiveness was only $17 \%$ after a $20-$ min washout. In this report, the results of previous electrophysiological experiments on MEPCs and EPCs and of new experiments with repetitive stimulations were used to estimate the ratio of open-channel inhibition (use dependent block) and allosteric inhibition in three computation models and correlated with the lipophilicy of the esters. It follows that all esters possess both forms of inhibition in differing ratios; the more lipophilic dibutyl esters act mostly as allosteric modulators, probably influencing receptors from the lipid annulus, while the less lipophilic esters mostly act as open channel blockers.

\section{Materials and Methods}

\section{Electrophysiology}

Experiments were carried out on isolated neuromuscular preparations from the sartorius of the adult frog Rana ridibunda, (30-50 g body mass) in the autumn-winter period in accordance with the ethical guidelines of the European Community for Animal Care and Exploitation. Animals were kept in the dark at an room temperature of $5-6^{\circ} \mathrm{C}$. Before beginning the experiment, animals were acclimatized at $20-22{ }^{\circ} \mathrm{C}$ for 3-4 hours and anaesthetized to the point of unresponsiveness by cooling on crushed ice. After decapitation, the spinal cord was immediately destroyed by pitching. The excised muscle with a 3-6 mm stump of nerve was fixed to the sylgard-covered bottom of a $5 \mathrm{ml}$ chamber, superfused at a rate of $2-3 \mathrm{ml} / \mathrm{min}$ with oxygenated Ringer solution and transversely cut near the endplate zones. This procedure led to muscle fiber depolarization to about $-50 \mathrm{mV}$ within 60-90 $\mathrm{min}$, prevented muscle contractions and thus enabled the recording of the high quantum endplate current EPCs (Volkova et al. 1975, Giniatullin et al. 1989, 2001). EPCs were recorded with a standard two-microelectrode voltage clamp. Signals were captured and averaged with a computer program (discrimination period $4 \mu \mathrm{s}$ ) (Galkin et al. 2001). The nerve was stimulated by rectangular supramaximal pulses with an amplitude of 0.5-2.0 mV and duration of $0.25 \mathrm{~ms}$. The amplitude and $\tau$ of the exponential current decay were calculated as described previously (Magazanik and Vyskočil 1969, Bukharaeva et al. 2002). The usual frequency of nerve stimulation was once per 15 seconds $(0.067 \mathrm{~Hz})$, two other frequencies of 0.008 and $60 \mathrm{~Hz}$ were also used during the experiments. Half-decay time of drug action on EPCs amplitude was estimated in each experiment from intersection between extrapolated lines of control EPCs, linear decline and steady state level of inhibition (e.g. Fig. 2B, dashed lines for dibutyl ester). Statistical analyses were performed using the independent t-test $(\mathrm{P}<0.01)$ of the program Microcal Origin 6.0 (OriginLab Corporation, Northampton, MA, USA). Data are expressed as mean \pm S.E.M. Differences between two means were determined using Student's t-test. Statistical significance was tested at $95 \%(\mathrm{P}<0.05)$ confidence level.

Drugs

Dimethyl, diethyl, dipropyl and dibutyl esters of DMOPA were synthesized in the Arbuzov Institute of Organic and Physical Chemistry RAS, Kazan, Russia. All other chemicals were from Sigma Chemical, St. Louis, MO.

\section{Half inhibition time}

For numerical characterization of channel inhibition rate we have fitted the time dependence of current amplitudes by the action of drugs with the Hilllike equation:

$$
A=\left(A_{b}-A_{e}\right) \cdot \frac{T_{1 / 2}{ }^{n}}{t^{n}+T_{1 / 2}{ }^{n}}+A_{e}
$$

where $A_{b}$ is the beginning current amplitude, $A_{e}$ is ending current amplitude, $T_{1 / 2}$ is half inhibition time. In other words half inhibition time is a time period between the start of drug action and the moment when the current amplitude attains to the average of beginning and ending amplitudes. The same method was used for estimation of amplitude recovery during washout of drugs.

\section{Computer simulation}

We used a computer simulation method based on the solution of ordinary differential equations (Chretien and Chauvet 1998, Shaihutdinova et al. 2009):

$$
\frac{d \bar{P}(t)}{d t}=\mathbf{Q} \cdot \bar{P}(t),
$$

where $\bar{P}(t)$ - vector of the probability of the existence of the receptor-channel complex in its various states, Q - the matrix of transitions between states. The current strength was considered to be proportional to the probability of transition of the complex to the openchannel state: 


$$
I(t)=\left(V-V_{e q}\right) \cdot N \cdot P_{\text {open }}(t) \cdot \sigma,
$$

where $\mathrm{V}-$ membrane potential, $\mathrm{V}_{\mathrm{eq}}-$ equilibrium potential, $\mathrm{N}$ - total quantity of channels on the membrane, $\mathrm{P}_{\text {open }}(\mathrm{t})$ - probability of existence of receptorchannel complex in the open-channel state, $\sigma$ conductivity of the single channel. Changes in agonist concentration in the synaptic cleft were described according to a recently published computational approach (Skorinkin et al. 2008).

\section{Results}

\section{Dependence of the decay time on stimulation}

Open channel inhibition can be detected as a shortening of quantal responses during repetitive stimulation, when nAChR channels are open for a longer period and allow the compound to enter the channel orifice and plug it for some time. If the modulating ester can enter and block the channel that has been opened by released $\mathrm{ACh}$, it should act faster at higher frequencies of stimulation; if it acts mostly allosterically, the frequency dependence of amplitude inhibition should be less or absent. Short, less lipophilic dimethyl ester and long, more lipophilic dibutyl ester were tested in this respect. Neuromuscular preparations were indirectly stimulated with a very low frequency, once per 2 minutes $(0.008 \mathrm{~Hz})$ and with a higher frequency, every 15 seconds $(0.067$ $\mathrm{Hz})$. During the low frequency stimulation $(0.008 \mathrm{~Hz})$ the depressive action of the less lipophilic dimethyl ester was very slow (the beginning of this is illustrated in Fig. 2A, open circles, $0.008 \mathrm{~Hz}$ bar); its half inhibition time was in fact $19.9 \pm 1.5 \mathrm{~min}$ as found in other five 30-45 $\mathrm{min}$ experiments (not shown in Fig. 2). The depressive effect significantly shortened to $6.5 \pm 0.7 \mathrm{~min}(\mathrm{n}=6)$ during the more frequent $0.067 \mathrm{~Hz}$ stimulation (illustrated in Fig. 2A, open circles, $0.067 \mathrm{~Hz}$ bar, from $10^{\text {th }} \mathrm{min}$ on).

In contrast, with the longer and more lipophilic dibutyl ester, the half inhibition time was less dependent on the stimulation frequency (illustrated in Fig. 2, part B). It was $10.3 \pm 0.9 \mathrm{~min}$ at $0.067 \mathrm{~Hz}$ stimulation $(\mathrm{n}=6)$; it increased, but not significantly, at $0.008 \mathrm{~Hz}$, when the half inhibition time was $11.5 \pm 1.1 \mathrm{~min}$ in eight separate experiments $(\mathrm{P}>0.05)$.

These data indicate that dimethyl ester mostly interacts with the channel lumen of nAChRs and dibutyl ester mostly with other non-luminal site(s). At first glance, it seems that there is very little open channel effect with dibutyl ester, but a definitive analysis could only be made after model application, as will be described later.
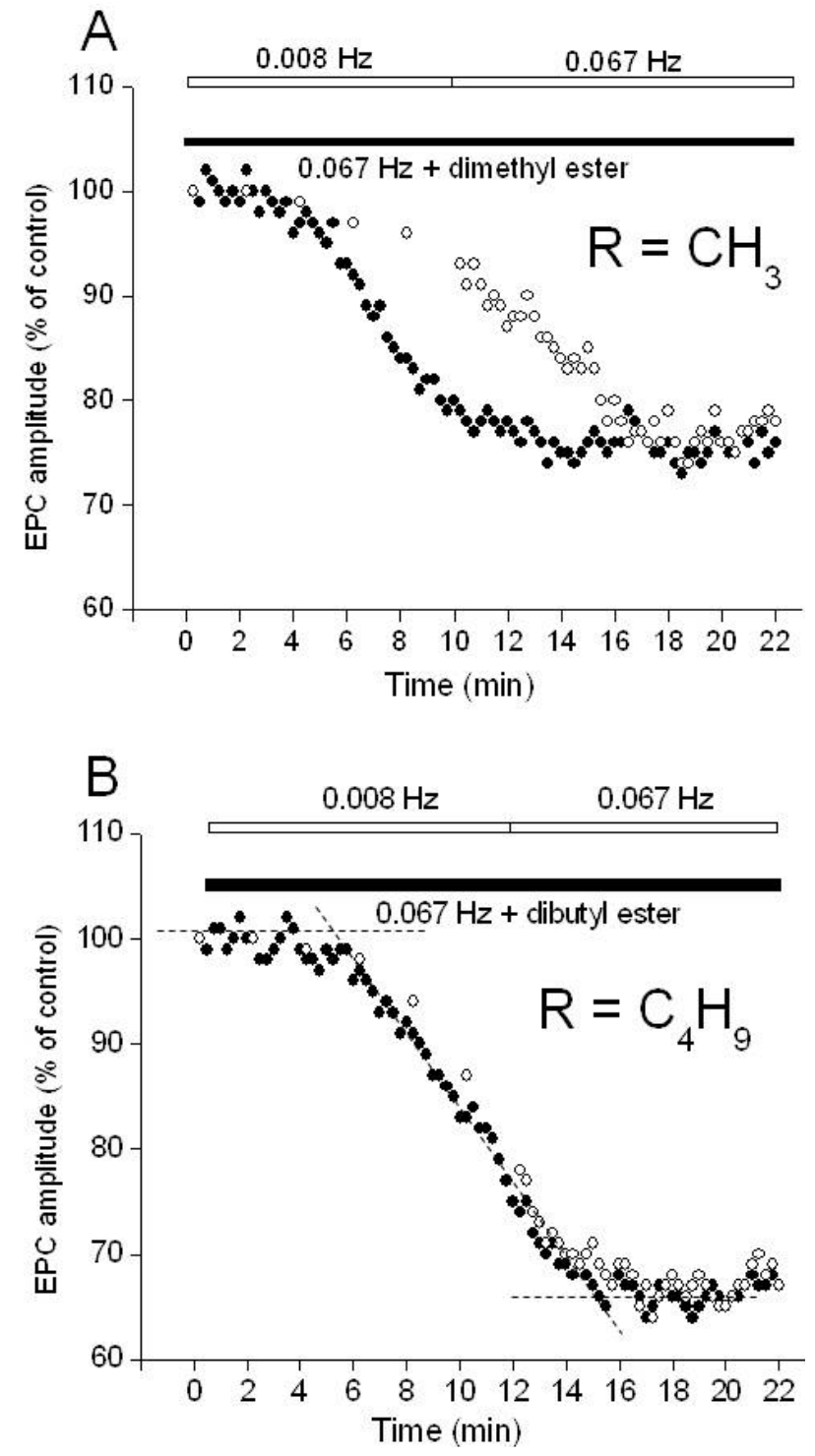

Fig. 2. A, Examples of effects of dimethyl ester $(100 \mu \mathrm{M})$, and $\mathbf{B}$, dibutyl ester $(100 \mu \mathrm{M})$ on EPC amplitude in individual endplate. Results are expressed as percentage of the initial EPC amplitude during continuous higher frequency $0.067 \mathrm{~Hz}$ stimulation (black circles, black bars). Open circles are EPC recordings which began during lower frequency stimulation $(0.008 \mathrm{~Hz})$ and continued during higher frequency $(0.067 \mathrm{~Hz})$ stimulation (open bars). EPC control amplitudes did not significantly differ in single experiments during both stimulation frequencies.

It was mentioned that all the esters have differing lipophilicities: their Overton-Meyer coefficients are $1.1,8.6,89.4$ and more than 1000 for dimethyl, diethyl, dipropyl and dibutyl ester, respectively. If esters also had a non-luminal site of action, their effects should be monotonically related to this coefficient.

In Figure 3, the averaged data of esters actions on EPC amplitude, EPC decay time constant and extent of ester washout versus Overton-Meyer coefficients are shown. For diethyl, dipropyl and dibutyl esters there is a monotonous dependence of the effect on the degree of 

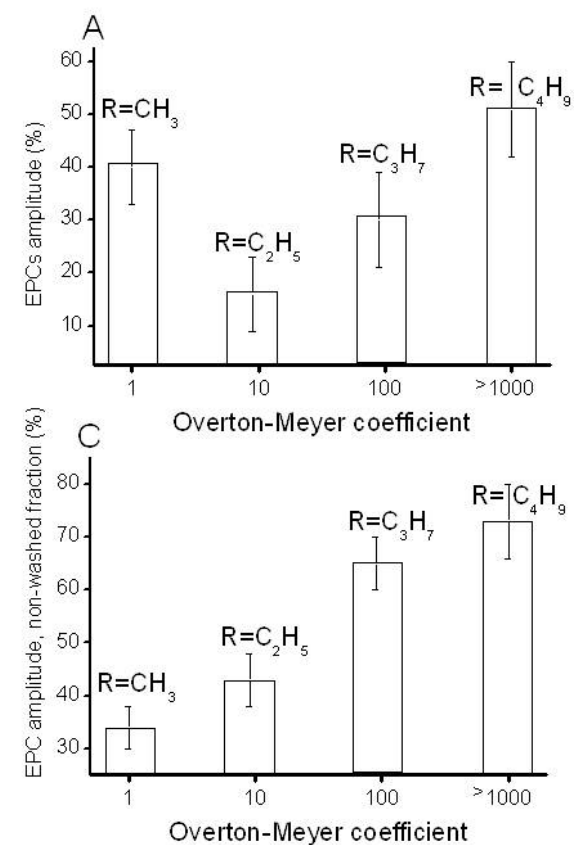
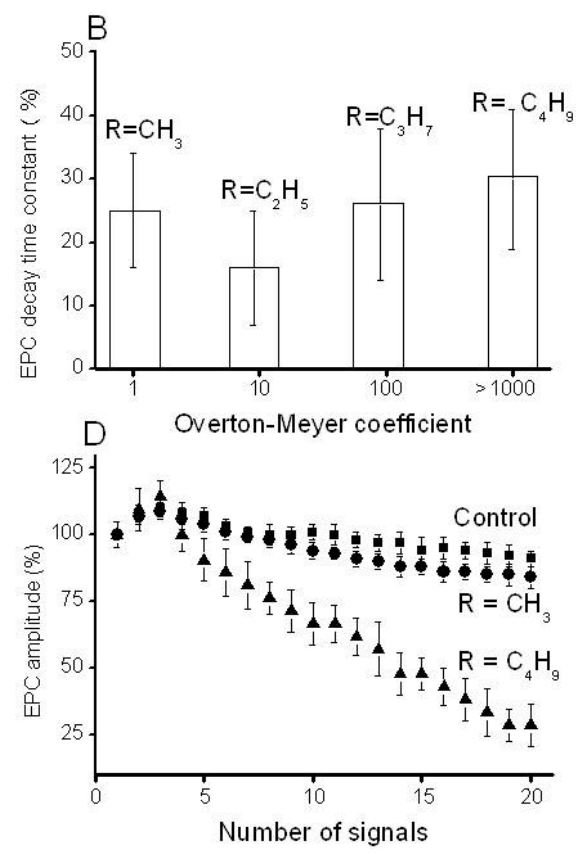

Fig. 3. EPC amplitude (A), decay time constant (B) and degree of drug washout (C, non-washed fraction of EPC amplitude inhibition as percentage of control amplitude) expressed as percentage of control values versus Overton-Meyer coefficients of the drugs (all applied at $500 \mu \mathrm{M}$ concentration, $\mathrm{n}=5-10$ ). Significantly different at probability level 0.05 were first and second columns on $A$ and second and fourth columns on $A$, first and second vs. third and fourth columns on C. Decay times showed only tendency to change but mean values were not significantly different. For diethyl ester, $\mu$ of fast decay component was presented. D, averaged series of EPC trains during high frequency stimulation $(60 \mathrm{~Hz})$ in controls (squares) before and after addition of $100 \mu \mathrm{M}$ dimethyl- (circles) and $100 \mu \mathrm{M}$ dibutyl- (triangles) esters. lipophilicity. But dimethyl ester only follows this trend in terms of the degree of EPC amplitude recovery after washout the drug (Fig. 3C) and is less effective at inhibiting the EPC amplitude and shortening the EPC decay (Fig. 3A, B). In other words this ester possessing a small lipophilicity is less effective as an inhibitor, but can be washed out quite well.

Trains of twenty EPCs were also evoked by $60 \mathrm{~Hz}$ nerve stimulation to check whether the dimethyl ester is a fast or slow open channel blocker and whether lipophilic dibutyl ester acts mostly as an allosteric inhibitor as suggested by Fig. 2. Under control conditions, the $20^{\text {th }}$ EPC in the train had on average an amplitude $9 \pm 2 \%$ smaller than the $1^{\text {st }}$ in the train (Fig. 3D, squares). According to a simple open channel block scheme (Skorinkin et al. 2004), slow (but not fast or medium) open channel blockers should deepen EPC depression. However, $100 \mu \mathrm{M}$ dimethyl ester only caused an insignificant attenuation of the depression by $16 \pm 4 \%$ $(\mathrm{n}=4, \mathrm{P}>0.05)$. On the other hand, $100 \mu \mathrm{M}$ dibutyl ester induced significant depression of the $20^{\text {th }}$ EPC by $65 \pm 6 \%$ $(\mathrm{P}<0.05, \mathrm{n}=5)$. Therefore dibutyl ester also has a slow open-channel blocking component in its depression.

The possible general loci of action are shown in Figure 4. The more lipophilic dibutyl ester acts more as an allosteric modulator, probably through the lipid bilayer, but it also has a channel blocking component of action. Less lipophilic dimethyl ester has the same two components of action but for this ester, the channel blocking component is dominant.

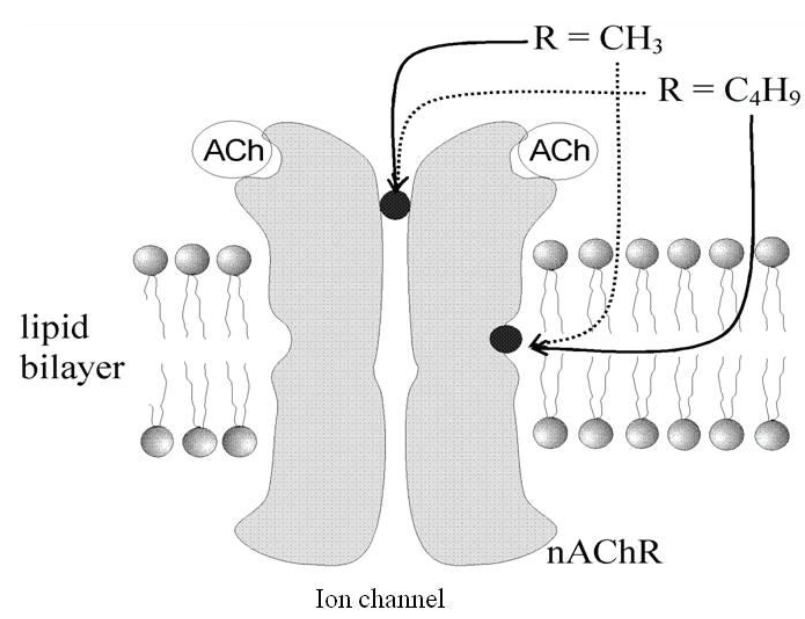

Fig. 4. Two possible action mechanisms of dimethyl and dibutyl ester.

\section{Quantification of the action by modeling}

Modeling should indicate whether the effects of the esters could be adequately described by either a simple open-channel block or by a more complex process involving allosteric influence. In order to verify this possibility and to find the most appropriate reaction constants for the interaction between the esters and the receptor-channel complex, we mathematically tested the kinetics of this interaction. In evaluating the adequacy of the model and experimental data, the following criteria were used: a) reproduction by the model of experimentally observed MEPC amplitude and decay time to steady state levels with 3 concentrations of compounds (Table 1), b) reproduction of experimentally 
observed EPC amplitude changes with high-frequency nerve stimulation $(60 \mathrm{~Hz})$; c) reproduction of the experimentally observed depressive activity of dibutyl ester with a low number of open channels (low frequency of stimulation). The computer model could be assessed to be adequate if it was able to reproduce the action of the drug in accordance with all the criteria outlined above. It was assumed that activation of the nAChR is accomplished according to the classical kinetic diagram (Colquhoun 1998):

$$
\mathrm{R}+\mathrm{A} \underset{\mathrm{k}_{1}^{-}}{\stackrel{\mathrm{k}_{1}^{+}}{\longleftrightarrow}} \mathrm{AR}+\mathrm{A} \underset{\mathrm{k}_{2}^{-}}{\stackrel{\mathrm{k}_{2}^{+}}{\longleftrightarrow}} \mathrm{A}_{2} \mathrm{R} \underset{\alpha}{\stackrel{\beta}{\longleftrightarrow}} \mathrm{A}_{2} \mathrm{R}^{\circ}
$$

where $\mathrm{k}_{1}^{+}, \mathrm{k}_{1}^{-}, \mathrm{k}_{2}^{+}, \mathrm{k}_{2}^{-}$are constants of association and dissociation of the agonist; $\beta, \alpha$ - constants of isomerization; $\mathrm{A}-$ agonist concentration, $\mathrm{R}$ and $\mathrm{R}^{\mathrm{o}}$ are the states of the receptor with the channel closed and open respectively. The reaction rate constants for $\mathrm{nAChRs}$ were taken from Stiles et al. (1999) (see legend to Table 1 for numbers). Three models were verified to describe the reduction of EPC and MEPC amplitude and time decay $\tau$ decrease during the action of esters.

\section{Model 1}

A simple diagram of open-channel blocking (Shen and Horn 1998):

$$
\mathrm{R}+\mathrm{A} \underset{\mathrm{k}_{1}^{-}}{\stackrel{\mathrm{k}_{1}^{+}}{\leftrightarrow}} \mathrm{AR}+\mathrm{A} \underset{\mathrm{k}_{2}^{-}}{\stackrel{\mathrm{k}_{2}^{+}}{\longleftrightarrow}} \mathrm{A}_{2} \mathrm{R} \underset{\alpha}{\stackrel{\beta}{\leftrightarrow}} \mathrm{A}_{2} \mathrm{R}^{\mathrm{o}}+\mathrm{B} \underset{\mathrm{k}_{\mathrm{b}}^{-}}{\stackrel{\mathrm{k}_{\mathrm{b}}^{+}}{\leftrightarrow}} \mathrm{A}_{2} \mathrm{RB}
$$

where $\mathrm{A}$ is the agonist concentration, $\mathrm{B}-$ is the ester concentration, $\mathrm{k}_{\mathrm{b}}^{+}-$is the inhibition constant in $\mathrm{mM}^{-1} \mathrm{~ms}^{-1}, \mathrm{k}_{\mathrm{b}}{ }^{-}$is the constant of unblocking in $\mathrm{ms}^{-1}$ and $\mathrm{A}_{2}$ $\mathrm{RB}$ represents the blocked $\mathrm{nAChR}$ complex in the presence of the agonist and inhibitor.

This model can reproduce the effect of dimethyl ester but it was unable to reproduce the reduction in EPC amplitude by dibutyl ester during low frequency stimulations, i. e. during rare channel openings. Using this model we cannot reproduce the changes in the amplitudes and time decays of MEPCs for diethyl, dipropyl and dibutyl esters either. This model therefore is not appropriate for a description of the action of all investigated esters. At the same time, a simple openchannel blocking model reproduced the amplification of EPC depression well during high-frequency stimulation, but only for slow blockers, when $\mathrm{k}_{\mathrm{b}}{ }^{-}<<\alpha$.

\section{Model 2}

In this model, the action of esters on amplitude and time decays is assumed to be an allosteric concentration-dependent modulation, that changes all the rate constants of the reactions (Liu et al. 1996):

$$
\mathrm{R}+\mathrm{A} \underset{\mathrm{k}_{1}^{-}(\mathrm{M})}{\stackrel{\mathrm{k}_{1}^{+}(\mathrm{M})}{\longleftrightarrow}} \mathrm{AR}+\mathrm{A} \underset{\mathrm{k}_{2}^{-}(\mathrm{M})}{\stackrel{\mathrm{k}_{2}^{+}(\mathrm{M})}{\leftrightarrow}} \mathrm{A}_{2} \mathrm{R} \underset{\alpha(\mathrm{M})}{\stackrel{\beta(\mathrm{M})}{\leftrightarrow}} \mathrm{A}_{2} \mathrm{R}^{\mathrm{o}}
$$

where $\mathrm{M}$ - modulator.

This model does not reproduce the depression of EPC amplitude by dibutyl ester during high-frequency nerve stimulation $(60 \mathrm{~Hz})$ or the two-phase EPC and MEPC decay caused by dimethyl ester. It also does not sufficiently explain the action of all investigated esters.
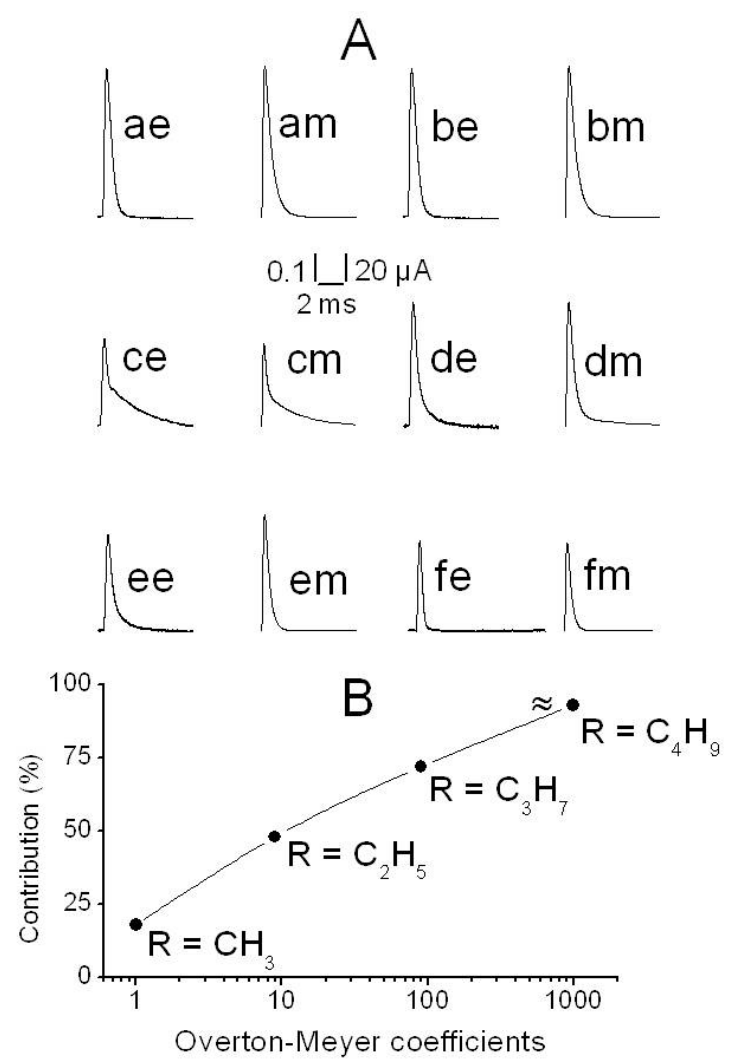

Fig. 5. A, Comparison of superposed experimental EPCs (ae, be, $\mathrm{ce}$, de, ee, fe, the same set of recordings as shown in Figure 1) and model EPCs constructed with model 3 (am, bm, cm, dm, em, fm); ae, am, control conditions; be, bm, 1,1-dimethyl-3-oxybutyl phosphonic acid; ce, cm, dimethyl ester; de, dm, diethyl ester; ee, em, dipropyl ester; fe, fm, dibutyl ester (500 $\mu \mathrm{M}$ for all esters). B, The contribution (in \% of total change) of the allosteric modulation in the resulting effect (Model 3) and its dependence on the lipophilicity of esters. All compounds in A and $B$ at a concentration of $500 \mu \mathrm{M}$, frequency of stimulation 0.067 $\mathrm{Hz}$. Amplitude calibration in $\mu \mathrm{A}$ for experimental EPCs and in arbitrary units for model EPCs.

\section{Model 3}

The effect of esters on the amplitude and time decay was interpreted with the use of a reaction scheme which combines the mechanism of open-channel 
Table 1. Experimental and model parameters of MEPCs amplitude and $\mathrm{T}$ of decay time during application of esters in three concentrations.

\begin{tabular}{|c|c|c|c|c|c|c|c|c|}
\hline \multirow[t]{2}{*}{ Compound } & \multirow[t]{2}{*}{$\begin{array}{c}\text { In } \\
\mu \mathrm{M}\end{array}$} & \multicolumn{2}{|c|}{$\begin{array}{l}\text { Amplitude of } \\
\text { MEPCs } \\
\text { (\% of control) }\end{array}$} & \multicolumn{2}{|c|}{$\begin{array}{c}\tau \text { of MEPCs decay time } \\
\text { ( } \% \text { of control) }\end{array}$} & \multirow[t]{2}{*}{$\begin{array}{c}\beta, \\
\mathbf{m s}^{-1}\end{array}$} & \multirow[t]{2}{*}{$\begin{array}{c}\mathbf{k}_{\mathbf{b}}^{+} \\
\mathbf{m} \mathbf{M}^{-1} \cdot \mathbf{m s}^{-1}\end{array}$} & \multirow[t]{2}{*}{$\begin{array}{c}\mathbf{k}_{\mathbf{b}}^{-} \\
\mathbf{m s}^{-1}\end{array}$} \\
\hline & & Experiment & Model & Experiment & Model & & & \\
\hline \multirow{3}{*}{$\begin{array}{l}\text { Dimethyl } \\
\text { ester }\end{array}$} & 10 & $-2 \pm 6$ & -2 & $-0 /+39 \pm 10$ & 3 & 36.7 & \multirow{3}{*}{6} & \multirow{3}{*}{1.0} \\
\hline & 100 & $-25 \pm 7$ & -19 & $-12 \pm 9 /+83 \pm 14$ & $-33 / 145$ & 29 & & \\
\hline & 500 & $-40 \pm 7$ & -47 & $-25 \pm 9 /+117 \pm 28$ & $-74 / 169$ & 26 & & \\
\hline \multirow{3}{*}{$\begin{array}{l}\text { Diethyl } \\
\text { Ester }\end{array}$} & 10 & $0 \pm 7$ & -1 & $0 \%$ & -1 & 36 & \multirow{3}{*}{0.9} & \multirow{3}{*}{0.2} \\
\hline & 100 & $-9 \pm 5$ & -10 & $-10 \pm 4$ & -15 & 28 & & \\
\hline & 500 & $-16 \pm 7$ & -21 & $-16 \pm 9$ & -30 & 25 & & \\
\hline \multirow{3}{*}{$\begin{array}{l}\text { Dipropyl } \\
\text { ester }\end{array}$} & 10 & $-6 \pm 8$ & -1 & $0 \%$ & -2 & 35 & \multirow{3}{*}{0.5} & \multirow{3}{*}{0.002} \\
\hline & 100 & $-15 \pm 8$ & -13 & $-17 \pm 9$ & -19 & 24 & & \\
\hline & 500 & $-30 \pm 9$ & -23 & $-26 \pm 12$ & -33 & 20 & & \\
\hline \multirow{3}{*}{$\begin{array}{l}\text { Dibutyl } \\
\text { Ester }\end{array}$} & 10 & $-11 \pm 5$ & -7 & $0 \%$ & -10 & 29 & \multirow{3}{*}{0.3} & \multirow{3}{*}{0.001} \\
\hline & 100 & $-26 \pm 10$ & -28 & $-17 \pm 7$ & -29 & 15 & & \\
\hline & 500 & $-51 \pm 9$ & -43 & $-30 \pm 11$ & -40 & 10 & & \\
\hline
\end{tabular}

When numbers are presented with the minus sign, the given parameter decreased by the indicated percentage. Experimental data in the presence of three concentrations of esters are based on a previous study (Pryazhnikov et al. 2005). $\mathrm{n}$ were usually 8-15. Bold numbers - the values differ significantly at $p=0.05$. For dimethyl ester, a two-exponential decay was found. The fast one had a $\mathrm{T}$ lower (minus) and the slow one had a T higher (plus) than the control MEPC. DMOPA was virtually ineffective and results with this generic compound are therefore not given. The following reaction rate constants were used during modeling to obtain the best fit with experiments cf. (Stiles et al. 1999): $\mathbf{k}_{1}^{+}=160.6 \mathrm{mM}^{-1} \cdot \mathrm{ms}^{-1}, \mathbf{k}_{1}^{-}=18.4 \mathrm{~ms}^{-1}, \mathbf{k}_{2}^{+}=80.3 \mathrm{mM}^{-1} \cdot \mathrm{ms}^{-1}, \mathbf{k}_{2}^{-}=36.8 \mathrm{~ms}^{-1}, \mathrm{a}=1.7 \mathrm{~ms}^{-1}, \beta=36.7 \mathrm{~ms}^{-1}$.

blocking with the mechanism of allosteric modulation (M), influencing the various reaction constants:

$$
\mathrm{R}+\mathrm{A} \underset{\mathrm{k}_{1}^{-}}{\stackrel{\mathrm{k}_{1}^{+}}{\leftrightarrow}} \mathrm{AR}+\mathrm{A} \underset{\mathrm{k}_{2}^{-}}{\stackrel{\mathrm{k}_{2}^{+}}{\leftrightarrow}} \mathrm{A}_{2} \mathrm{R} \underset{\alpha}{\stackrel{\beta(\mathrm{M})}{\longleftrightarrow}} \mathrm{A}_{2} \mathrm{R}^{\mathrm{o}}+\mathrm{B} \underset{\mathrm{k}_{\mathrm{b}}^{-}}{\stackrel{\mathrm{k}_{b}^{+}}{\leftrightarrow}} \mathrm{A}_{2} \mathrm{RB}
$$

An ester was regarded both as open-channel blocker B and as allosteric modulator M. All criteria concerning multiquantal EPC and single-quantum MEPC could be met if only one channel opening time constant $\beta$ is modulated. This model adequately reproduces EPCs in control and ester-affected endplates, including twophase decay with dimethyl ester (Fig. 5B).

The model precisely reproduced EPC amplitude changes during high-frequency stimulation $(60 \mathrm{~Hz})$ and the action of dibutyl ester during rare channel openings (data not given). Although with less precision, the model also reproduced experimentally obtained data of MEPC amplitude and decay time changes with three concentrations of esters. All described experimental effects were reproduced in model 3 with the set of constants given in Table 1.

It follows from the model that the action of less lipophilic dimethyl ester can be described as predominantly an open channel block ( $82 \%$ of the total inhibition), and this portion decreases for the more lipophilic esters: diethyl (52\%), dipropyl (27\%) and dibutyl (4\%). We can conclude that the activity of dibutyl ester is mostly due to its modulating features while dimethyl ester acts mostly as an open channel blocker.

\section{Discussion}

The action of DMOPA derivatives on EPC amplitude and time course was tested and explained by two complementary mechanisms - slow open channel and allosteric inhibition. Mathematical modeling revealed that all esters combine both mechanisms of EPC and MEPC depression: allosteric modulation of the receptorchannel complex and a block of the open channel. According to the effects of dibutyl ester on the decay in EPC amplitude during slow and high frequency stimulation, the small portion of the open-channel blockade of this most lipophilic compound can be classified as a slow noncompetitive blocker (Buisson and Bertrand 1998). However, it can also affect the nicotinic 
receptor-channel complex, even if ion channels were closed (at rest) or inhibited. It can probably easily penetrate into the hydrophobic part of the lipid membrane and inhibit the functioning of the receptor-channel complex cf. (Yeagle 1989, Barrantes 1993, Walcher et al. 2001, Cannon et al. 2003). One of the possible mechanisms of such a modification is the modulation of membrane dipole potential, as has been shown for other amphiphilic compounds (Cladera and O'Shea 1998), but this remains to be proved.

It is known that the dependence of inhibitory activity on the frequency of stimulation is characteristic of an open channel blocker, usually a charged and less lipophilic molecule (Ogden et al. 1981). However, this dependence on high-frequency stimulation was in fact only found in the most lipophilic dibutyl ester (Fig. 3D). Nevertheless, computer simulation resolved this apparent paradox. Increasing the frequency of stimulation can potentiate the EPC amplitude inhibition in trains only in the case of so-called slow open-channel blockers, when $\mathrm{k}_{\mathrm{b}}{ }^{-}<<\alpha$ and the apparent forward rate for block is very slow (Buisson and Bertrand 1998, Schober et al. 2010). But dimethyl ester is evidently a medium type of openchannel blocker, the effect of which is only mildly dependent on the frequency of stimulation. This is indicated by the fact that, according to model 3 , the constant $\mathrm{k}_{\mathrm{b}}{ }^{-}(=1)$ is close to $\alpha(=1.7$, Table 1$)$. On the other hand, the dibutyl as well as the dipropyl and diethyl esters (the latter two not shown on Fig. 3D) are slow open-channel blockers, because they exhibit a very low $\mathrm{k}_{\mathrm{b}}{ }^{-} / \alpha$ ratio (Table 1 ) and their inhibitory action increases with high-frequency stimulation and frequent opening of the receptor channels (Fig. 3D).

Table 1 shows the dependence of the reaction rate constant of channel opening $\beta$ on the concentration of esters. These esters only differ in the length of their carbon chains and the resulting lipophilicity (Fig. 1 and $5 \mathrm{~B})$. We can therefore propose that the modulation of $\beta$ is due to the differing lipid solubility and reflects actual concentration of the ester in the membrane during its particular concentrations in extracellular solution. The changes of $\beta$ with concentration and degree of lipophilicity also support the possibility of an allosteric action of the esters on the receptor from the adjacent lipid annulus. The slow washout of dibutyl and dipropyl esters acting mainly as allosteric inhibitors (according to model 3) can be also explained by their higher lipophilicity, since they can stay dissolved in the lipid membrane and inhibit nAChR channel for longer time, even when they disappear extracellularly. In this case, the transition of ester molecules back to the water phase would be very slow. These esters can therefore be designated as lipid-soluble allosteric modulators (Custodio et al. 2008).

\section{Conflict of Interest}

There is no conflict of interest.

\section{Acknowledgements}

We are grateful to Dr. Andrey Vizel and Dr. Lyubov Schukina from the A. E. Arbuzov Institute of Organic and Physical Chemistry RAS, Kazan, Russia, for generously donating the homologous 1,1-dimethyl-3-oxybutyl phosphonic acid derivatives and Dr. Rashid Giniatullin and Dr. Jan Krůšek for comments and suggestions during the preparation of this manuscript. This work was supported by a Leading Scientific School grant of the Russian Federation and RFBR grants. The contribution of F. V. was covered by IAA500110905, GAČR 202/09/0806 and AV0Z 0110509.

\section{References}

BARRANTES FJ: Lipid effects on nicotinic acetylcholine receptor gating and kinetics: a structural-functional correlation. Braz J Med Biol Res 26: 553-571, 1993.

BERÁNEK R, VYSKOČIL F: The action of tubocurarine and atropine on the normal and denervated rat diaphragm. J Physiol 188: 53-66, 1967.

BUISSON B, BERTRAND D: Open-channel blockers at the human alpha4beta2 neuronal nicotinic acetylcholine receptor. Mol Pharmacol 53: 555-563, 1998.

BUKHARAEVA EA, SAMIGULLIN D, NIKOLSKY E, VYSKOČIL F: Protein kinase A cascade regulates quantal release dispersion at frog muscle endplate. $J$ Physiol 538: 837-848, 2002.

CANNON B, HERMANSSON M, GYORKE S, SOMERHARJU P, VIRTANEN JA, CHENG KH: Regulation of calcium channel activity by lipid domain formation in planar lipid bilayers. Biophys $J$ 85: 933-942, 2003. 
CHRETIEN JM, CHAUVET GA: An algorithmic method for determining the kinetic system of receptor-channel complexes. Math Biosci 147: 227-257, 1998.

CLADERA J, O'SHEA P: Intramembrane molecular dipoles affect the membrane insertion and folding of a model amphiphilic peptide. Biophys $J$ 74: 2434-2442, 1998.

COLQUHOUN D: Binding, gating, affinity and efficacy: the interpretation of structure-activity relationships for agonists and of the effects of mutating receptors. Br J Pharmacol 125: 924-947, 1998.

CUSTODIO JM, WU CY, BENET LZ: Predicting drug disposition, absorption/elimination/ transporter interplay and the role of food on drug absorption. Adv Drug Deliv Rev 60: 717-733, 2008.

GINIATULLIN RA, KHAMITOV G, KHAZIPOV R, MAGAZANIK LG, NIKOLSKY EE, SNETKOV VA, VYSKOČIL F: Development of desensitization during repetitive end-plate activity and single end-plate currents in frog muscle. J Physiol 412: 113-122, 1989.

GINIATULLIN RA, TALANTOVA MV, VYSKOČIL F: The role of desensitisation in decay time of miniature endplate currents in frogs Rana ridibunda and Rana temporaria. Neurosci Res 39: 287-292, 2001.

GRUTTER T, CHANGEUX JP: Nicotinic receptors in wonderland. Trends Biochem Sci 26: 459-463, 2001.

KRU゚ŠEK J: Allostery and cooperativity in the interaction of drugs with ionic channel receptors. Physiol Res 53: 569$579,2004$.

KRŮŠEK J, DITTERT I, HENDRYCH T, HNÍK P, HORÁK M, PETROVIC M, SEDLÁČEK M, SUŠÁNKOVÁ K, SVOBODOVÁ L, TOUŠOVÁ K, UJEC E, VLACHOVÁ V, VYKLICKÝ L, VYSKOČIL F, VYKLICKÝ L JR: Activation and modulation of ligand-gated ion channels. Physiol Res 53: S103-S113, 2004.

LIU SQ, LAW FY, KNAUF PA: Effects of external $\mathrm{pH}$ on substrate binding and on the inward chloride translocation rate constant of band 3. J Gen Physiol 107: 271-291, 1996.

MAGAZANIK LG, NIKOLSKY E, VYSKOČIL F: Effect of the desensitization-potentiating agent SKF-525a on frog end-plate currents. Eur J Pharmacol 80: 115-119, 1982.

MAGAZANIK LG, VYSKOČIL F: Different action of atropine and some analogues on the end-plate potentials and induced acetylcholine potentials. Experientia 25: 618-619, 1969.

MAGLEBY KL, STEVENS CF: The effect of voltage on the time course of end-plate currents. J Physiol 223: 151-171, 1972.

OGDEN DC, SIEGELBAUM SA, COLQUHOUN D: Block of acetylcholine-activated ion channels by an uncharged local anaesthetic. Nature 289: 596-598, 1981.

PENIONZHKEVICH D, GORBUNOV FE: New technologies of neurometabolic therapy of cerebrovascular diseases (in Russian). Zh Nevrol Psikhiatr Im S S Korsakova 109: 19-22, 2009.

PENIONZHKEVICH D, GORBUNOV FE, OGANESIAN VR: Dimephosphon-electrophoresis with sinusoidal modulated currents as a new method of physiotherapy in clinical practice (in Russian). Vopr Kurortol Fizioter Lech Fiz Kult 1: 28-30, 2004.

PRYAZHNIKOV EG, SKORINKIN AI, GARAEV RS, GINIATULLIN RA, VIZEL AO, SHCHUKINA LI: Mechanisms of the effect of 1,1-dimethyl-3-hydroxybutyl phosphonic acid derivatives on synaptic transmission in neuromuscular junction. Bull Exp Biol Med 139: 437-440, 2005.

ROMANELLI MN, GUALTIERI F: Cholinergic nicotinic receptors: competitive ligands, allosteric modulators, and their potential applications. Med Res Rev 23: 393-426, 2003.

SHAIHUTDINOVA AR, NIKOLSKY EE, VYSKOČIL F, SKORINKIN AI: Mechanisms of the inhibition of endplate acetylcholine receptors by antiseptic chlorhexidine (experiments and models). Naunyn Schmiedebergs Arch Pharmacol 380: 551-560, 2009.

SHEN WX, HORN JP: Mecamylamine selectively blocks nicotinic receptors on vasomotor sympathetic C neurons. Brain Res 788: 118-124, 1998.

SCHOBER A, SOKOLOVA E, GINGRICH KJ: Pentobarbital inhibition of human recombinant alpha1A P/Q-type voltage-gated calcium channels involves slow, open channel block. Br J Pharmacol 161: 365-383, 2010.

SKORINKIN AI, OSTROUMOV KB, SHAIKHUTDINOVA AR, GINIATULLIN RA: Trapping blockage of muscle nicotinic cholinoreceptors by mecamilamine. Dokl Biol Sci 399: 464-466, 2004.

SKORINKIN AI, SHAIHUTDINOVA AR, VYSKOČIL F: Model of concentration changes across the synaptic cleft during a single quantum release. Gen Physiol Biophys 27: 19-24, 2008. 
STILES JR, KOVYAZINA IV, SALPETER EE, SALPETER MM: The temperature sensitivity of miniature endplate currents is mostly governed by channel gating: evidence from optimized recordings and Monte Carlo simulations. Biophys J 77: 1177-1187, 1999.

SVOBODOVÁ L, KRŮŠEK J, HENDRYCH T, VYSKOČIL F: Physostigmine modulation of acetylcholine currents in COS cells transfected with mouse muscle nicotinic receptor. Neurosci Lett 401: 20-24, 2006.

TALY A, CORRINGER PJ, GUEDIN D, LESTAGE P, CHANGEUX JP: Nicotinic receptors: allosteric transitions and therapeutic targets in the nervous system. Nat Rev Drug Discov 8: 733-750, 2009.

VOLKOVA IN, NIKOL'SKII EE, POLETAEV GI: Blocking the action potentials and contractions of skeletal muscle in frogs by muscle fiber transection (in Russian). Fiziol Zh SSSR Im IM Sechenova 61: 1433-1436, 1975.

WALCHER S, ALTSCHUH J, SANDERMANN H JR: The lipid/protein interface as xenobiotic target site: kinetic analysis of the nicotinic acetylcholine receptor. J Biol Chem 276: 42191-42195, 2001.

YEAGLE PL: Lipid regulation of cell membrane structure and function. FASEB J 3: 1833-1842, 1989.

ZWART R, VIJVERBERG HP: Potentiation and inhibition of neuronal nicotinic receptors by atropine: competitive and noncompetitive effects. Mol Pharmacol 52: 886-895, 1997. 